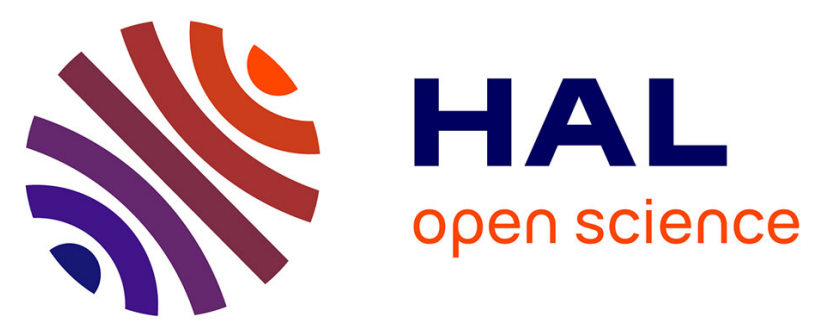

\title{
Mechanical behavior of recrystallized Zircaloy-4 under monotonic loading at room temperature: Tests and simplified anisotropic modeling
}

Nathanael Mozzani, Quentin Auzoux, D. Le Boulch, Eric Andrieu, Christine Blanc, Colin Scott, Nathalie Barnel

\section{To cite this version:}

Nathanael Mozzani, Quentin Auzoux, D. Le Boulch, Eric Andrieu, Christine Blanc, et al.. Mechanical behavior of recrystallized Zircaloy-4 under monotonic loading at room temperature: Tests and simplified anisotropic modeling. Journal of Nuclear Materials, 2014, vol. 447 (n 1-3), pp. 94-106. 10.1016/j.jnucmat.2014.01.003 . hal-01179433

\section{HAL Id: hal-01179433 \\ https://hal.science/hal-01179433}

Submitted on 22 Jul 2015

HAL is a multi-disciplinary open access archive for the deposit and dissemination of scientific research documents, whether they are published or not. The documents may come from teaching and research institutions in France or abroad, or from public or private research centers.
L'archive ouverte pluridisciplinaire HAL, est destinée au dépôt et à la diffusion de documents scientifiques de niveau recherche, publiés ou non, émanant des établissements d'enseignement et de recherche français ou étrangers, des laboratoires publics ou privés. 


\section{OATAO}

\section{Open Archive TOULOUSE Archive Ouverte (OATAO)}

OATAO is an open access repository that collects the work of Toulouse researchers and makes it freely available over the web where possible.

This is an author-deposited version published in : http://oatao.univ-toulouse.fr/ Eprints ID : 14024

To link to this article : DOI:10.1016/j.jnucmat.2014.01.003

URL : http://dx.doi.org/10.1016/j.jnucmat.2014.01.003

\section{To cite this version :}

Mozzani, Nathanael and Auzoux, Quentin and Le Boulch, D. and Andrieu, Eric and Blanc, Christine and Scott, Colin and Barnel, Nathalie Mechanical behavior of recrystallized Zircaloy-4 under monotonic loading at room temperature: Tests and simplified anisotropic modeling. (2014) Journal of Nuclear Materials, vol. 447 (n 1-3). pp. 94-106. ISSN 0022-3115

Any correspondence concerning this service should be sent to the repository administrator: staff-oatao@listes-diff.inp-toulouse.fr 


\title{
Mechanical behavior of recrystallized Zircaloy-4 under monotonic loading at room temperature: Tests and simplified anisotropic modeling
}

\author{
N. Mozzani ${ }^{\mathrm{a}, \mathrm{d}, *}$, Q. Auzoux ${ }^{\mathrm{a}}$, D. Le Boulch ${ }^{\mathrm{a}}$, E. Andrieu ${ }^{\mathrm{b}}$, C. Blanc ${ }^{\mathrm{b}}$, C.P. Scott ${ }^{\mathrm{c}}$, N. Barnel ${ }^{\mathrm{d}}$ \\ ${ }^{a}$ CEA Saclay, DEN/DMN/SEMI/LCMI, 91191 Gif-sur-Yvette, France \\ ${ }^{\mathrm{b}}$ Université de Toulouse, CIRIMAT/ENSIACET, UPS/INPT/CNRS, 4 allée Emile Monso, 31432 Toulouse Cedex 4, France \\ 'AREVA, AREVA NP, 10 rue Juliette Récamier, 69456 Lyon, France \\ ${ }^{\mathrm{d}}$ EDF RED, Site des Renardières, 77818 Moret-sur-Loing, France
}

\begin{abstract}
A B S T R A C T
Mechanical behavior of recrystallized Zircaloy- 4 was studied at room temperature in the rolling-transverse plane of a thin sheet. Uniaxial constant elongation rate tests (CERTs) were performed along with creep tests, over a wide range of strain rates. Based on a simplified formulation, different sets of parameters for an anisotropic viscoplastic model were found to fit the stress-strain curves. Notched specimen tensile tests were carried out with a digital image correlation (DIC) technique in order to determine the strain field evolution. From these measurements and the determination of Lankford coefficients, the most consistent model was selected and simulated data were successfully compared with the experimental observations.
\end{abstract}

\section{Introduction}

Zirconium-based alloys were chosen as the fuel cladding material in pressurized water reactors (PWRs) due to their low neutron absorption cross-section, mechanical strength and corrosion resistance. It is also used in the chemical and medical industry because of its corrosion and bio-compatibility properties. The fracture modes of zirconium alloys in various aggressive environments have been widely studied and notably the iodine-induced stress corrosion cracking (I-SCC).

I-SCC has been extensively studied in the laboratory, at high temperatures $\left(>300^{\circ} \mathrm{C}\right)$ in iodine vapor usually by internal pressure tests (IPT) on tubes. Fewer studies have been carried out in iodine-containing methanol solutions at room temperature and at atmospheric pressure. These showed similarities with the high temperature vapor environment in the cracking behavior. In iodine vapor, the mechanical conditions were found to have a great influence on the cracking susceptibility. A few authors have reported on the influence of stress biaxiality on I-SCC in iodine vapor $[1,2]$, using combined internal pressure and tensile tests. In these studies, the influence of stress biaxiality on I-SCC was studied through the fracture strains which take into account both crack initiation and propagation steps. However the influence of biaxiality on crack initiation is yet to be studied. Moreover, since the transgranular crack propagation stage depends strongly on the crystallographic texture, the overall ductility is impacted by this parameter $[3,4]$.

* Corresponding author at: EDF R\&D, Site des Renardières, 77818 Moret-surLoing, France. Tel.: +33 160737984 .

E-mail address: nathanael.mozzani@edf.fr (N. Mozzani).
The strain rate effect on I-SCC in iodine vapor has also been studied by several authors $[5,6]$. A decrease in the deformation at fracture was observed when the strain rate became lower than $10^{-4} \mathrm{~s}^{-1}$. No such studies have been carried out in iodized methanol solutions.

The present paper is part of a study dedicated to determining the influence of stress biaxiality ratios and strain rates on I-SCC of recrystallized Zircaloy-4 deformed in iodized methanol solutions. The ultimate aim of this study is to predict the probability of crack initiation on the basis of calculated stress and strain fields and then to validate this predictive model by observing experimental crack positions. The experimental I-SCC studies at various stress biaxiality ratios and strain rates are not presented in the present paper. Round-notched flat tensile test specimens were used because of the material shape (thin sheet). In this case, mechanical fields are strongly non-uniform, especially along the ligament between the two notches (stress and strain concentration at the notch, higher stress biaxiality in the center of the ligament...). In this framework, a reliable mechanical behavior model was needed to describe the stress and strain fields in such specimens and then correlate the crack initiation location to local mechanical states. Constitutive equations of the material were defined and parameters of these laws were identified.

\section{Experimental}

\subsection{Material}

Fully recrystallized Zircaloy- 4 in the form of a thin sheet (thickness $t=478 \mu \mathrm{m}$ ) was provided by AREVA-Cezus. The chemical 
composition in weight percent was $1.3 \% \mathrm{Sn}, 0.21 \% \mathrm{Fe}, 0.11 \% \mathrm{O}, \mathrm{Zr}$ balance. EBSD mapping was carried out to determine the grain size distribution. The grains were equiaxed with an average size of $4.1 \mu \mathrm{m}$. The material crystallographic texture, induced by the fabrication process, was quantified using X-ray diffraction. The pole figures obtained were standard for cold-rolled and recrystallized zirconium alloys. It was observed that most of the basal poles were aligned in the normal $(\mathrm{N})$ - transverse $(\mathrm{T})$ plane, with a mean angle from the normal direction (ND) of $32.5^{\circ}$. The computed Kearns factors were: $\left(f_{N}, f_{T}, f_{R}\right)=(0.61,0.25,0.14)$ where $R$ is the rolling direction.

\subsection{Mechanical tests procedure}

Smooth and notched tensile specimens were cut from the sheet by spark machining. Two different types of notched specimens were used, i.e., $\mathrm{R} 1.0$ and $\mathrm{R} 0.5$, with $1 \mathrm{~mm}$ and $0.5 \mathrm{~mm}$ notch radii respectively. Smooth and notched samples were cut in both the transverse (TD) and rolling directions (RD). The specimen geometries are detailed in Fig. 1. The tests were carried out under laboratory air environment at controlled temperature $\left(22^{\circ} \mathrm{C}\right)$ on an electromechanical ZWICK Z020D tensile machine equipped with a $1 \mathrm{kN}$ load cell. The relative uncertainty in the conventional stress was less than $1.75 \%$; it was less than $0.25 \%$ on the displacement and the displacement rate. A $10 \mathrm{~mm}$ INSTRON gauge length extensometer was used in the first tests on smooth specimens to check that the crosshead displacement gave an accurate estimation of the plastic strain of the specimen once corrected for the loading line compliance.

For smooth specimens, constant elongation rate tests (CERTs) were performed: the conventional strain rates $\dot{\epsilon}$ were $10^{-\mathrm{j}} \mathrm{s}^{-1}$ with $j=\{6,5,4,3,2\}$. Additional tests with strain rate jumps were performed between the $10^{-5} \mathrm{~s}^{-1}, 10^{-4} \mathrm{~s}^{-1}$ and $10^{-3} \mathrm{~s}^{-1}$ rates to check the influence of plastic strain on the material viscosity. The experimental conditions for these tests are summarized in Table 1.

Creep tests were also carried out on smooth specimens at stress levels close to the yield strength. Specimens were loaded at a constant strain rate equal to $10^{-4} \mathrm{~s}^{-1}$ until the target stress was reached. The load was then maintained until fracture or the userdefined end of test. The considered load stresses were chosen

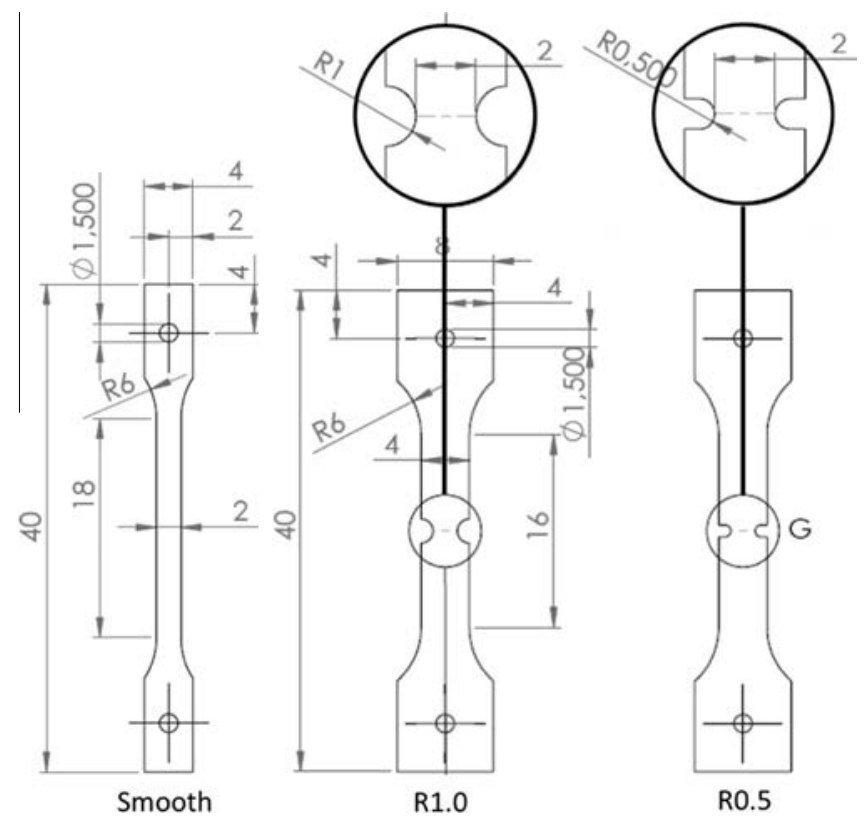

Fig. 1. Specimen geometries. Dimensions are expressed in millimeters. between $85 \%$ and $110 \%$ of the room temperature (RT) $0.2 \%$ proof stress at the loading strain rate. The set of creep testing conditions is given in Table 2, together with the secondary creep rates.

Tests performed on notched specimens were constant displacement rate tests. The macroscopic strain $E$ was defined by dividing the displacement by the notch diameter. A constant macroscopic strain rate $\dot{E}$ of $10^{-4} \mathrm{~s}^{-1}$ was used in these trials. The set of testing conditions for notched specimens is given in Table 3 .

A 2D digital image correlation (DIC) technique was used to characterize in situ the strain fields during tests on notched specimens. It was also used for two smooth specimen CERTs (one in the TD and one in the RD) to study the plastic anisotropy. The DIC software CorrelmanuV was developed at the Solid Mechanics Laboratory (LMS) of the Ecole Polytechnique (Palaiseau - France) [7]. DIC notched specimens were painted in white with a random pattern of black dots whereas the DIC smooth tensile specimens were used in the as-received state. Tensile tests were filmed at an acquisition rate of 30 frames per second and a resolution of 1280 pixels $\times 1024$ pixels. For the smooth specimens, the optical zoom gave a scaled resolution of $2.55 \mu \mathrm{m} /$ pixel whereas it was $4.35 \mu \mathrm{m} /$ pixel for the (wider) notched specimens. A correlation domain was a group of pixels whose position was followed from one picture to the following and was used to compute the strains. The theoretical uncertainty on the position of the domains was lower than one pixel (sub-pixel interpolation). The distance between two neighboring domains was between 21 and 25 pixels ( $<65 \mu \mathrm{m}$ for the smooth specimens, $<110 \mu \mathrm{m}$ for the notched specimens). This gave an estimate of the gauge length used for the local strain calculation. The overall absolute accuracy of local strain measurements by this method was estimated to be \pm 0.01 [8].

\subsection{Mechanical test results}

In this section, the results of the mechanical tests performed are summarized and compared to previously published data. Keyparameters used to build the mechanical behavior model are also discussed.

\subsubsection{Yield strength and strain hardening}

The results of tensile tests on smooth specimens in the TD and the RD (true stress versus plastic strain curves) are shown in Figs. 2 and 3 respectively. Characteristic values are summarized in Table 1 with $0.2 \%$ offset proof stress YS, ultimate tensile stress $\sigma_{u}$, uniform plastic elongation $\varepsilon_{u}$ and final plastic strain $\varepsilon_{f}$. Engineering values are given. In Fig. 2, for the TD, a marked peak followed by a slight softening at the beginning of plasticity was observed, independent of the strain rate. In the case of the RD (Fig. 3), the softening part was no longer visible so that a plateau was observed. This effect is commonly observed for recrystallized zirconium alloys at room temperature and higher. Dunlop suggested that it was caused by an initial shortage of mobile dislocations and the existence of a population of dislocations pinned on solute atoms in the material [9]. Their unpinning at the onset of plasticity would cause the load drop. Twinning is sometimes cited as the cause for the peak/drop but Geyer showed that this deformation mechanism is only activated after several percents of plastic strains, in both axial and circumferential directions of a tube [10]. The difference of behavior in this early stage of plasticity with the direction is not clearly explained and cannot be related to differences of glide systems activation [10]. For the studied material, at a strain rate of $10^{-4} \mathrm{~s}^{-1}$, the yield strength was $354 \mathrm{MPa}$ and $394 \mathrm{MPa}$ in the RD and TD respectively. Furthermore, the engineering ultimate tensile strength $\sigma_{u}$ was $456 \mathrm{MPa}$ in the RD and $433 \mathrm{MPa}$ in the TD. At a strain rate of $10^{-3} \mathrm{~s}^{-1}, \mathrm{YS}^{\mathrm{RD}}, \mathrm{YS}^{\mathrm{TD}}, \sigma_{u}^{\mathrm{RD}}$ and $\sigma_{u}^{\mathrm{TD}}$ were equal to $379 \mathrm{MPa}$, $418 \mathrm{MPa}, 481 \mathrm{MPa}$ and $453 \mathrm{MPa}$ respectively. At all strain rates, the yield strength was lower for the RD than for the TD; however, 
Table 1

List of CERTs and strain rate jump tests of smooth specimens, values given are engineering stresses and strains.

\begin{tabular}{|c|c|c|c|c|c|c|c|}
\hline Test direction & $\dot{\epsilon}\left(\mathrm{s}^{-1}\right)$ & YS (MPa) & $\sigma_{u}(\mathrm{MPa})$ & $\epsilon_{u}^{p}(\%)$ & $\epsilon_{f}^{p}(\%)$ & Specimen name & DIC \\
\hline $\mathrm{RD}$ & $10^{-6}$ & 309.3 & nd $^{b}$ & $\mathrm{nd}^{\mathrm{b}}$ & $9.9^{\mathrm{a}}$ & A1L1-17 & no \\
\hline $\mathrm{RD}$ & $10^{-5}$ & 330.8 & 431.6 & 12.5 & 39.7 & A1L1-3 & no \\
\hline $\mathrm{RD}$ & $10^{-5}$ & 332.2 & 432.9 & 14 & 40.8 & A1L1-8 & no \\
\hline $\mathrm{RD}$ & $10^{-4}$ & 354.0 & 455.6 & 13.9 & $26.3^{\mathrm{a}}$ & A1L1-2 & no \\
\hline $\mathrm{RD}$ & $10^{-4}, 10^{-5}, 10^{-3}$ & $356.4\left(10^{-4} \mathrm{~s}^{-1}\right)$ & $478.3\left(10^{-3} \mathrm{~s}^{-1}\right)$ & 13.3 & 35.6 & A1L1-18 & no \\
\hline $\mathrm{RD}$ & $2 \times 10^{-4}$ & 356.7 & 457.9 & 13.4 & 30.8 & A1L1-6 & yes \\
\hline $\mathrm{RD}$ & $10^{-3}$ & 378.9 & 480.4 & 13 & $25.6^{\mathrm{a}}$ & A1L1-1 & no \\
\hline $\mathrm{RD}$ & $10^{-2}$ & 396.8 & 490.8 & 11.7 & 24.4 & A1L1-4 & no \\
\hline TD & $10^{-6}$ & 343.2 & 388.6 & 9.4 & $15.2^{\mathrm{a}}$ & A2T1-1 & no \\
\hline TD & $10^{-5}$ & 361.0 & 403.2 & 8.9 & $17.9^{\mathrm{a}}$ & A1T1-15 & no \\
\hline TD & $10^{-5}$ & 370.4 & 408.1 & 8.9 & $19.9^{\mathrm{a}}$ & A2T1-9 & no \\
\hline TD & $10^{-4}$ & 393.8 & 433.1 & 9.2 & 24 & A1T1-10 & no \\
\hline TD & $10^{-4}, 10^{-5}, 10^{-3}$ & $395.4\left(10^{-4} \mathrm{~s}^{-1}\right)$ & $457.2\left(10^{-3} \mathrm{~s}^{-1}\right)$ & 9.3 & $18.9^{\mathrm{a}}$ & A2T1-8 & no \\
\hline TD & $2 \times 10^{-4}$ & 401.1 & 439.0 & 10.5 & 25.7 & A1T1-29 & yes \\
\hline TD & $10^{-3}$ & 415.8 & 450.8 & 9.1 & 27.5 & A1T1-11 & no \\
\hline TD & $10^{-3}$ & 420.2 & 454.9 & 9.6 & 23.5 & A2T1-4 & no \\
\hline TD & $10^{-2}$ & 448.2 & 472.0 & 8.6 & 20.7 & A2T1-7 & no \\
\hline TD & $10^{-2}$ & 448.7 & 473.9 & 8.5 & 19.8 & A1T1-16 & no \\
\hline TD & $10^{-2}$ & 452.1 & 475.2 & 8.1 & 20.4 & A2T1-5 & no \\
\hline
\end{tabular}

a Unbroken specimen, end of test value.

b Test interrupted before determination.

Table 2

List of creep tests, true strains.

\begin{tabular}{|c|c|c|c|c|c|}
\hline Test direction & $\sigma_{\text {imposed }}(\mathrm{MPa}) /\left(\%\right.$ of $\left.R p_{0.2 \%}\right)$ & $\dot{\epsilon}_{\text {secondary }}^{p}\left(\mathrm{~s}^{-1}\right)$ & $\epsilon_{f}^{p}(\%)$ & Final time (s) & Specimen name \\
\hline $\mathrm{RD}$ & $335 / 94.6$ & $3.97 \times 10^{-8}$ & $3.46^{\mathrm{a}}$ & 228,457 & A1L1-16 \\
\hline $\mathrm{RD}$ & $366 / 103.4$ & $1.26 \times 10^{-7}$ & $5.0^{\mathrm{a}}$ & 93,281 & A1L1-14 \\
\hline $\mathrm{RD}$ & $387 / 109.3$ & $2.48 \times 10^{-7}$ & $8.3^{\mathrm{a}}$ & 97,335 & A1L1-15 \\
\hline $\mathrm{RD}$ & $387 / 109.3$ & $6.52 \times 10^{-7}$ & $6.0^{\mathrm{a}}$ & 25,029 & A1L1-20 \\
\hline TD & $332 / 84.3$ & $5.05 \times 10^{-8}$ & $6.3^{\mathrm{a}}$ & 448,819 & A2T1-17 \\
\hline TD & $377 / 95.7$ & $5.27 \times 10^{-7}$ & 16.4 & 160,523 & A2T1-13 \\
\hline TD & $377 / 95.7$ & $5.84 \times 10^{-7}$ & $10.6^{\mathrm{a}}$ & 94,190 & A1T1-30 \\
\hline TD & $397 / 100.8$ & $4.01 \times 10^{-6}$ & 18 & 25,766 & A2T1-10 \\
\hline TD & $397 / 100.8$ & $3.01 \times 10^{-6}$ & 24.3 & 36,702 & A1T1-28 \\
\hline TD & $408 / 103.5$ & $1.07 \times 10^{-5}$ & $15.2^{\mathrm{a}}$ & 8547 & A2T1-11 \\
\hline TD & $418 / 106.1$ & $\mathrm{nd}^{\mathrm{b}}$ & $6.8^{\mathrm{a}}$ & 851 & $\mathrm{~A} 1 \mathrm{~T} 1-27$ \\
\hline TD & $418 / 106.1$ & $2.02 \times 10^{-5}$ & 16.6 & 4867 & A2T1-12 \\
\hline
\end{tabular}

a Unbroken specimen, end of test value.

b nd: not determined.

Table 3

List of constant displacement rate tests of notched specimens, all were followed by DIC.

\begin{tabular}{|c|c|c|c|c|c|c|c|}
\hline Test direction & Specimen type & $\dot{E}\left(\mathrm{~s}^{-1}\right)$ & $\Sigma_{\max }(\mathrm{MPa})$ & $E^{p}\left(\Sigma_{\max }\right)(\%)$ & $E_{\text {final }}^{p}(\%)$ & Specimen name & $E_{\text {End,of DIC }}^{p}(\%)$ \\
\hline TD & $\mathrm{R} 1.0$ & $10^{-4}$ & 546.2 & 8.6 & 35.9 & A2T12-1 & 8 \\
\hline TD & R0.5 & $10^{-4}$ & 569.8 & 21.4 & 75.0 & A2T13-1 & 19 \\
\hline $\mathrm{RD}$ & $\mathrm{R} 1.0$ & $10^{-4}$ & 559.1 & 12.2 & 35.1 & A2L12-1 & 15 \\
\hline RD & R0.5 & $10^{-4}$ & 609 & 32.7 & 65.5 & A2L13-1 & 25 \\
\hline
\end{tabular}

the ultimate tensile strength was higher for the RD than for the TD showing that the strain hardening was greater in the rolling direction. Consequently, the stress-strain curves crossed one another at approximately $3 \%$ of plastic strain as shown in Fig. 4. Therefore, the results clearly showed an anisotropic behavior due to the crystallographic texture of the material and the limited number of active slip systems of the hexagonal close-packed (HCP) structure, in good agreement with the literature. Indeed, as shown by [11] and [12], the thermomechanical properties are known to vary nonlinearly with the loading direction in the RD-TD plane. Moreover, the mechanical properties were found to be in agreement with the data published by Grange for a recrystallized Zircaloy- 4 tested at room temperature: $\mathrm{YS}^{\mathrm{RD}}, \mathrm{YS}^{\mathrm{TD}}, \sigma_{u}^{\mathrm{RD}}$ and $\sigma_{u}^{\mathrm{TD}}$ were given equal to $411 \mathrm{MPa}, 422 \mathrm{MPa}, 522 \mathrm{MPa}$ and $484 \mathrm{MPa}$ respectively [12]. Differences between our results and those from the literature could be explained taking into account the texture. Indeed, in Grange's study, the material had a slightly more radial texture than in the present work, leading to a smaller difference between the rolling and transverse directions.

It was also noticed that the uniform strain $\varepsilon_{\mathrm{u}}$ was higher for the RD (about 13\%) than for the TD (about 9\%) in agreement with the observations of Mahmood and Murty [13]. These authors found an $\varepsilon_{u}^{\mathrm{RD}}$ value of $14 \%$ and an $\varepsilon_{u}^{\mathrm{TD}}$ value of $7 \%$ for a strain rate of $1.610^{-4} \mathrm{~s}^{-1}$. Grange found $\varepsilon_{u}^{\mathrm{RD}}$ and $\varepsilon_{u}^{\mathrm{TD}}$ values equal to $11.3 \%$ and $10.4 \%$ respectively at $10^{-3} \mathrm{~s}^{-1}$, confirming the same trend [12].

\subsubsection{Plastic deformation anisotropy}

As stated previously before, a strong anisotropy of the mechanical behavior was observed due to the limited active slip systems of the HCP structure. This result was often found in the literature. 


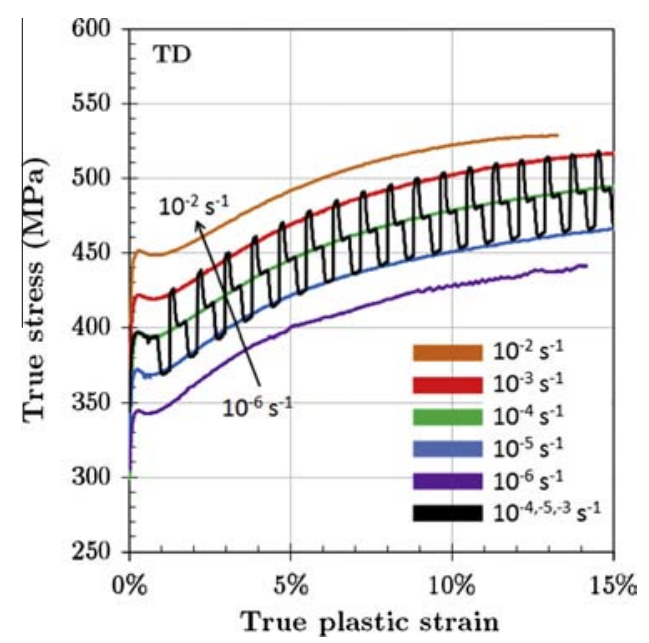

Fig. 2. CERTs of smooth specimens in the transverse direction (TD) along with the strain rate jump test.

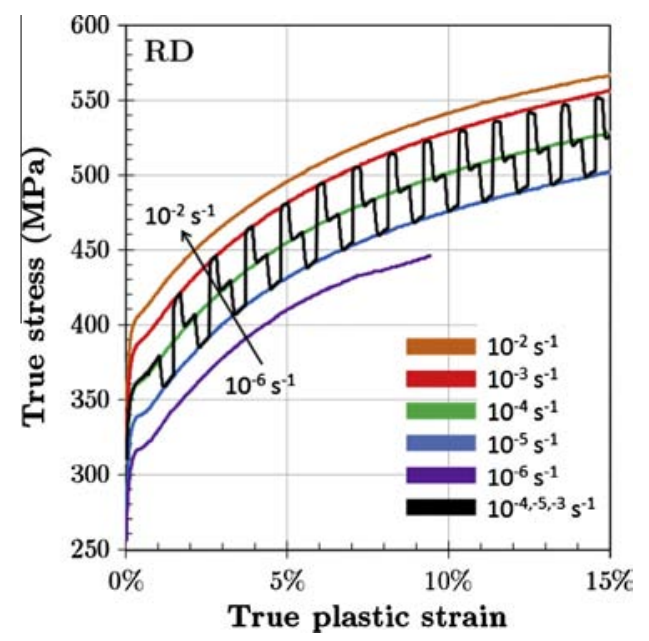

Fig. 3. CERTs of smooth specimens in the rolling direction (RD) along with the strain rate jump test.

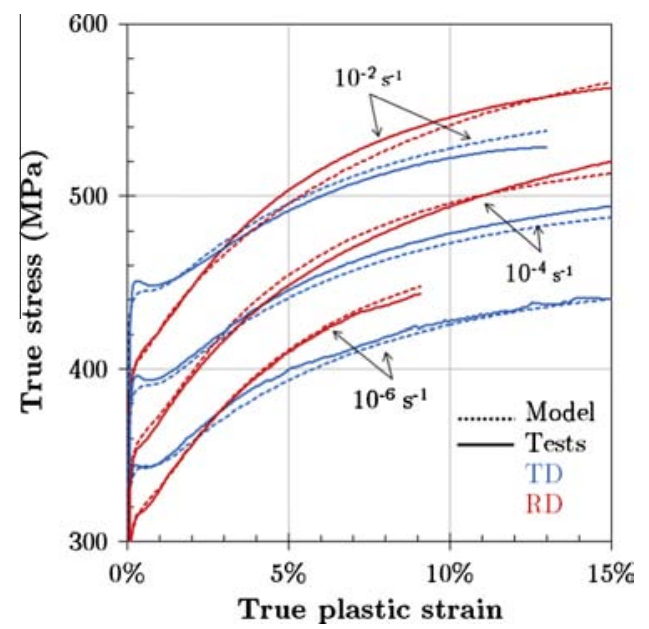

Fig. 4. Uniaxial tensile tests of smooth specimens in the RD (red) and TD (blue) at three strain rates. Comparison with the best-fitting model (dashed lines). (For interpretation of the references to color in this figure legend, the reader is referred to the web version of this article.)
Geyer studied the slip system activation at different levels of equivalent plastic strain on recrystallized Zircaloy-4 tubes (at room temperature and with similar textures) stressed in the axial, circumferential and equibiaxial directions [10]. Up to $1 \%$ of equivalent plastic strain, only prismatic glide was observed when the stress was applied in the axial direction whereas some pyramidal gliding and twinning were already activated in the other stress states. The relative intensities of all the activated slip systems differed with the stress direction.

Another consequence of the material texture is the plastic deformation anisotropy. Plastic deformation does not easily occur along the $c$-axis of the HCP unit cell. Most basal poles are oriented normal to the sheet plane so that little reduction of the specimen thickness was expected during the tests. The ratios of plastic strains for in-plane deformation are very different from the isotropic case. One way to measure this plastic anisotropy for uniaxial tests is to look at the Lankford coefficients, also referred as the contractile strain ratio. For a tensile test, the Lankford coefficient for the considered loading direction $(l)$ is defined by:

$L_{l}=\frac{\partial \epsilon_{w}^{p}}{\partial \epsilon_{t}^{p}}=\frac{\left|\partial \epsilon_{w}^{p} / \partial \epsilon_{l}^{p}\right|}{1-\left|\partial \epsilon_{w}^{p} / \partial \epsilon_{l}^{p}\right|}$

where $\epsilon_{l}^{p}, \epsilon_{w}^{p}$ and $\epsilon_{t}^{p}$ are respectively the plastic strain in the loading $(l)$, width $(w)$ and thickness $(t)$ directions. When the material behavior is isotropic, this coefficient equals 1 . Two CERTs on smooth specimens with in situ DIC were performed to measure the Lankford coefficients of the sheet, strained in the RD and one for the TD (Table 1). The strain rate was $210^{-4} \mathrm{~s}^{-1}$. For these experiments, plastic strains were measured in the loading and width directions for strains up to $10 \%$. The results are shown in Fig. 5 along with the isotropic case. The computed Lankford coefficients were found to be constant in the studied range of plastic strains and to differ from one direction to another with $\mathrm{L}_{\mathrm{RD}}$ equal to $3.54 \pm 0.40$ whereas $\mathrm{L}_{\mathrm{TD}}$ was $4.41 \pm 0.50$. Similar values were found by Grange, i.e., 3.3 and 4.5 for the RD and the TD directions [12]. Mahmood found nearly the same values for the two directions, i.e., $\mathrm{L}_{\mathrm{RD}}$ equal to 3.88 and $\mathrm{L}_{\mathrm{TD}}$ to 3.72 [13]. In these two studies, the grid analysis technique was used. Differences between studies could arise from different crystallographic textures responsible for material anisotropy. Mahmood also mentioned the constancy of the Lankford coefficients with the level of strain whereas, for a Zr702 sheet studied at room temperature, Allais et al. observed a strong increase of the coefficients at the beginning of plasticity $(0-3 \%)$; then, the values

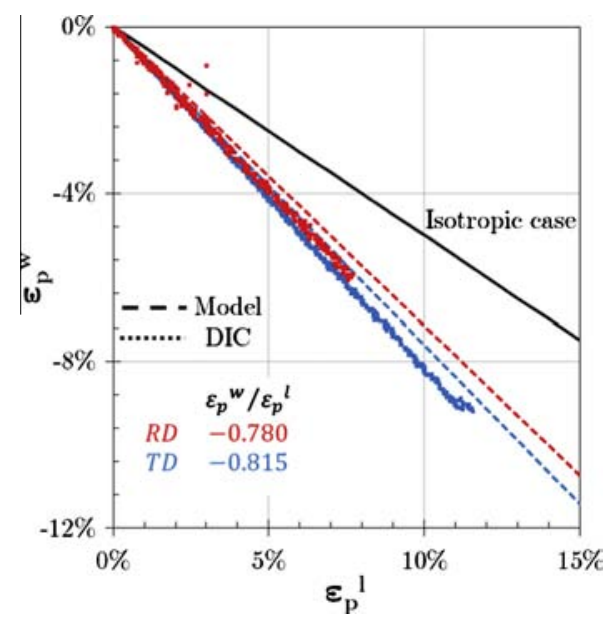

Fig. 5. Determination of the Lankford coefficients from plastic strain measurements in the loading $\left(\varepsilon_{p}^{l}\right)$ and width directions $\left(\varepsilon_{p}^{w}\right)$ by digital image correlation (DIC) on smooth specimens in the TD (lower line) and the RD (upper line). Comparison with the best-fitting model (dashed lines). 
were found to converge to a stabilized value [11]. This effect was not explained and might be related to different measurement techniques.

\subsubsection{Strain rate sensitivity and creep}

The strain-stress curves from Figs. 2 and 3 clearly show the material viscoplastic behavior at room temperature. The viscosity appeared to be isotropic. Strain rate jump tests showed that it remained unaffected by plastic strain up to the onset of necking. To quantify this effect, the strain rate sensitivity parameter was introduced:

$m=\frac{\partial \ln \sigma}{\partial \ln \dot{\epsilon}}$

This parameter measured the change of flow stress $\sigma$ with the strain rate $\dot{\epsilon}$. The determination of $\mathrm{m}$ from the yield strengths is shown in Fig. 6. A value of $0.030 \pm 0.006$ was found. It was positive because an increase of strain rate led to an increase of flow stress. Similar values were reported for recrystallized Zircaloy- 4 at room temperature; Elbachiri found $m=0.029$ [14], and from the yield strength versus strain data reported by Grange, a value of 0.027 was computed [12]. A slight decrease of the uniform elongation (between $1.5 \%$ and $2 \%$ ) with an increase of strain rate was also observed (Table 1).

In order to explore very low strain rates, creep tests were performed on smooth TD and RD specimens for nominal stresses in the range of $84-110 \%$ of the RT $0.2 \%$ proof stress at a loading strain rate of $10^{-4} \mathrm{~s}^{-1}$. Tests characteristics are given in Table 2 . These tests enabled material testing down to $510^{-8} \mathrm{~s}^{-1}$. The creep curves for the TD and the RD are given in Figs. 7 and 8 respectively. In spite of the low temperature, creep was found to be significant, leading to rupture in less than $30 \mathrm{~h}$ for some of the TD specimens. For the same load to yield stress ratio, the RD appeared to be less sensitive to creep. No rupture occurred for $48 \mathrm{~h},\left(>10^{5} \mathrm{~s}\right)$, even when the load holding plateau began after $2 \%$ of plastic strain at $10^{-4} \mathrm{~s}^{-1}$ (the case with a ratio of $109.3 \%$ of the $10^{-4} \mathrm{~s}^{-1} 0.2 \%$ proof stress).

When possible, secondary creep strain rates were determined from time-strain curves. In the TD, values of secondary creep rate ranged between $510^{-8} \mathrm{~s}^{-1}$ and $210^{-5} \mathrm{~s}^{-1}$ for stress between $88 \%$ and $106 \%$ of the direction $0.2 \%$ proof stress. In the RD, strain rates were found between $410^{-8} \mathrm{~s}^{-1}$ and $6.510^{-7} \mathrm{~s}^{-1}$, for stresses in the range $94-109 \%$ of the $0.2 \%$ proof stress. For a better comparison

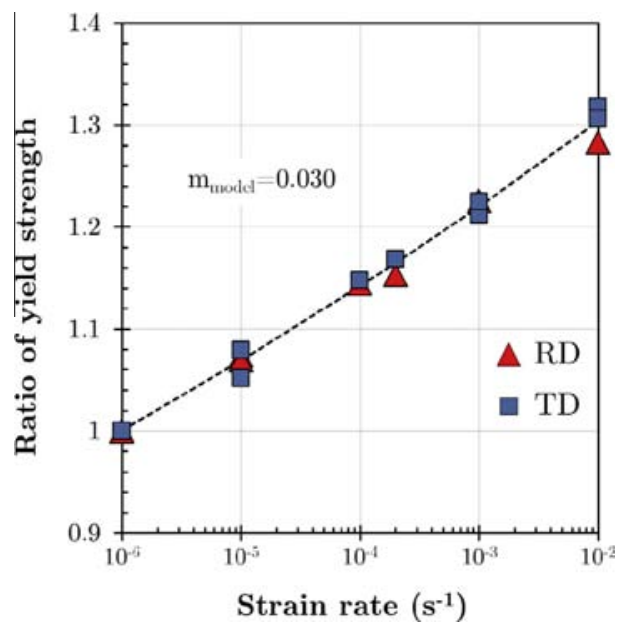

Fig. 6. Ratio of yield strength versus strain rate, taking $10^{-6} \mathrm{~s}^{-1}$ yield strength as a reference for each direction (309.3 MPa for the RD and 343.3 MPa for the TD). Superposition of data from the RD (triangles) and the TD (squares). Comparison with the best-fitting model (dashed lines)

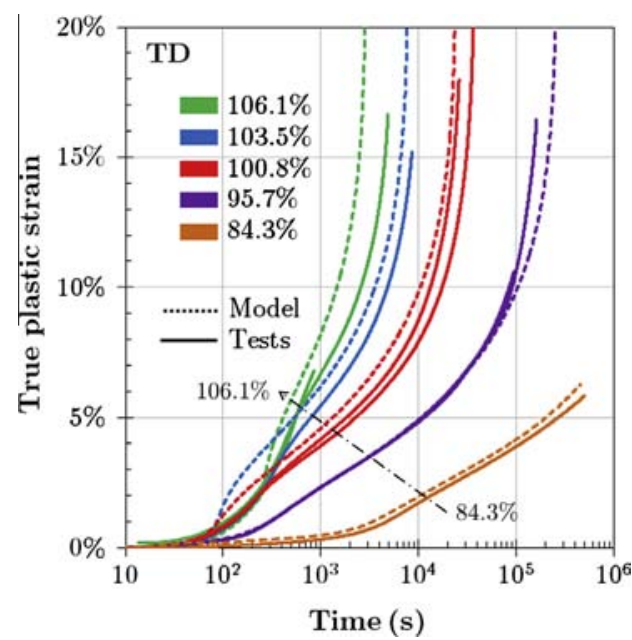

Fig. 7. Uniaxial creep tests of smooth samples at room temperature in the TD along with model predictions. The applied stresses are given as a percentage of the $10^{-4} \mathrm{~s}^{-1} 0.2 \%$ proof stress, $394 \mathrm{MPa}$.

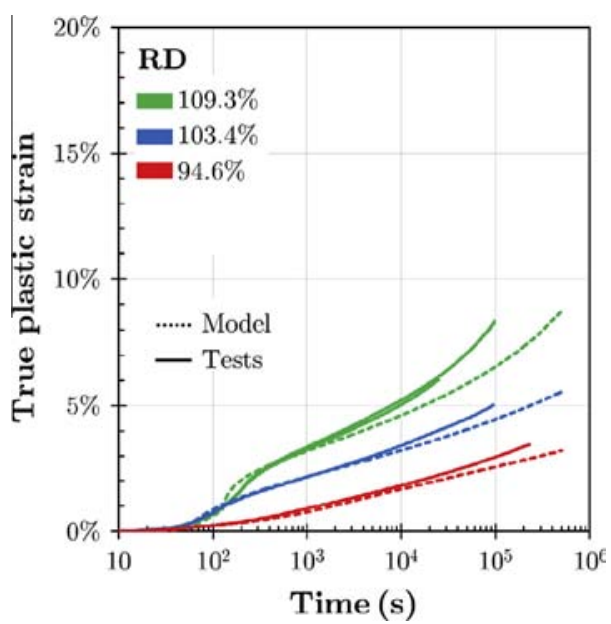

Fig. 8. Uniaxial creep tests of smooth samples at room temperature in the RD along with model predictions. The applied stresses are given as a percentage of the $10^{-4} \mathrm{~s}^{-1} 0.2 \%$ proof stress, $354 \mathrm{MPa}$.

between the two tested directions, secondary creep rates are plotted versus the applied stress in Fig. 9. For a given stress, the creep rate is greater in the TD than in the RD despite higher yield strength. Such behavior was already reported in recrystallized $\mathrm{Zr}$ alloys at room temperature for relative high stresses [15]. It could be linked to an easier activation of prismatic glide in the TD [10] and to the fact that the secondary creep regime is attained after some plastic strain. Since the strain hardening rate is greater in the RD for low strains, the difference in yield strength is lowered.

The strain rate sensitivity could then be computed with the true stress values from the different tests, at a given plastic strain in the secondary creep regime. This computation was carried out with creep tests in the TD, as shown in Fig. 10. The strain rate sensitivity parameter $m$ was 0.029 , very close to the one computed from the CERTs, confirming that a simple law could represent the material viscosity over the whole experimental domain.

\subsubsection{Notched specimen tests}

As mentioned previously, notched specimens tests were characterized by in situ DIC. Under the given experimental conditions, the DIC software was not able to compute the strain fields beyond a 


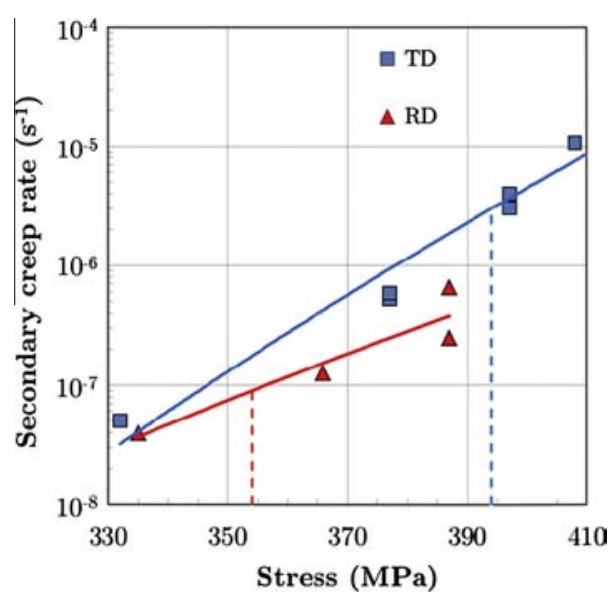

Fig. 9. Comparison of secondary creep rates for both RD (red) and TD (blue) directions as a function of stress. The solid lines are the best fit linear functions and the dashed ones indicate the direction $0.2 \%$ proof stress. (For interpretation of the references to color in this figure legend, the reader is referred to the web version of this article.)

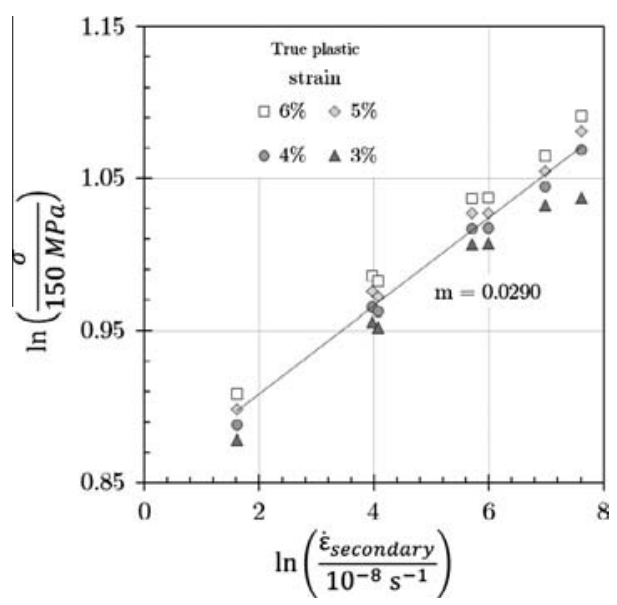

Fig. 10. Strain rate effect for creep tests in the TD. Logarithm of normalized stress versus logarithm of normalized secondary creep strain rate.

certain macro deformation (Table 3). The last column of Table 3 gives the macroscopic strain from which DIC computation was no longer possible.

From DIC performed on smooth specimens, it was possible to check the accuracy of the measurement: DIC plastic strain in the loading direction was compared to that computed from the machine crosshead displacement. The absolute difference was found to be \pm 0.003 . Since the scaled resolution of the pictures from notched specimen tests was almost twice that of the smooth specimen tests, one could estimate the accuracy at \pm 0.006 for these experiments. This is compatible with the estimated value of \pm 0.01 from [8].

Macroscopic stress-strain curves for the R0.5 notched specimens are given in Fig. 11. The same trend as for the smooth specimens was evidenced: the yield strength was higher for the TD than the RD, but the strain hardening rate was greater for the latter. The principal stress during these tests was clearly oriented in the loading direction. The same trends were observed for the R1.0 notched specimens.

The non-uniform distribution of strains is shown in Fig. 12 for the TD R0.5 specimen at $E^{P}=16 \%$. From these measurements, strain profiles were extracted along the ligament between the notches. These profiles are shown in Figs. 13 and 14 for local strains in

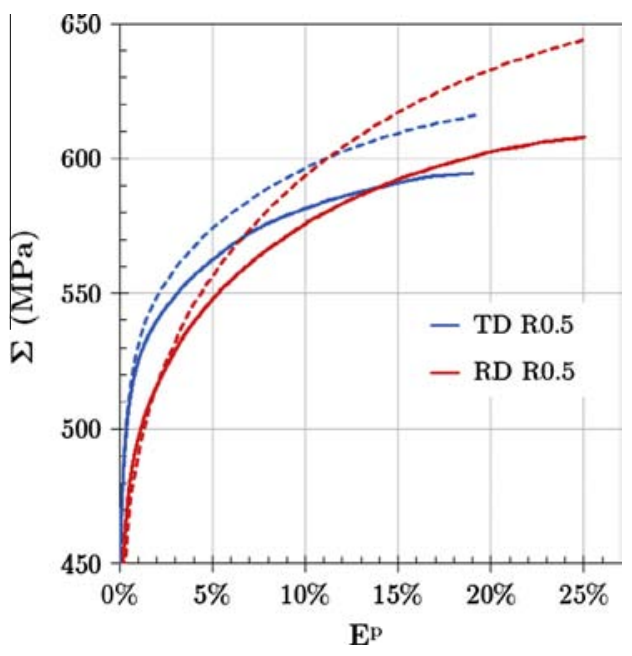

Fig. 11. Stress strain curves for R0.5 notched specimens, cut in the TD (blue) and the RD (red). Nominal stress $\Sigma$ is the load divided by the initial section between the notches. Curves are plotted up to the end of DIC. Comparison with the best-fitting model (dashed lines). (For interpretation of the references to color in this figure legend, the reader is referred to the web version of this article.)

the loading (TD) and width (RD) directions respectively. Due to the presence of notches, deformation was strongly non-uniform and concentrated at the notch tips, with strain values as high as $30 \%$. Near the center of the ligament, the profiles were rather flat, with a minimum at the center. The minimum was as low as $15 \%$ of the notch tip values. These profiles were used to benchmark the different mechanical behavior models described in the following section. The ligament was chosen because it was the most likely spot for crack initiation: stresses were maximal and strain was concentrated at notch tips.

\section{Model}

\subsection{Constitutive equations}

A generalized anisotropic and viscoplastic model was proposed. This model was developed with the Mistral module of Finite Element Method (FEM) software Cast3M [16]. The total strain was defined as the sum of an isotropic elastic strain and an anisotropic viscoplastic strain. To account for the material anisotropy described previously, the Hill's equivalent stress $\sigma_{H}$ was introduced [17]. This equivalent stress and its different extensions have been successfully used to describe the plastic loci anisotropy for zirconium alloys in previous studies [18-20]:

$\sigma_{H}(\underline{\underline{\sigma}})=\sqrt{\underline{\underline{\sigma}}: \underline{\underline{\underline{\underline{M_{H}}}}}: \underline{\underline{\sigma}}}=\sqrt{[\sigma]^{s} \cdot\left[M_{H}\right] \cdot[\sigma]^{s}}$

$M_{H}$ is a symmetric fourth order tensor defined with the Hill coefficients of the principal orthotropic directions of the sheet. The mathematical notation is explained here: a symmetric second order

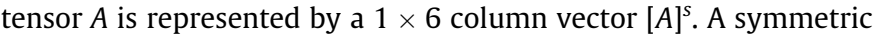
fourth order tensor $B$ is represented by a $6 \times 6$ matrix $[B]$.

$\left[M_{\left.H_{(N, T, R)}\right]}\right]=\left(\begin{array}{cccccc}H_{T}+H_{R} & -H_{R} & -H_{T} & 0 & 0 & 0 \\ -H_{R} & H_{R}+H_{N} & -H_{N} & 0 & 0 & 0 \\ -H_{T} & -H_{N} & H_{N}+H_{T} & 0 & 0 & 0 \\ 0 & 0 & 0 & H_{T R} & 0 & 0 \\ 0 & 0 & 0 & 0 & H_{R N} & 0 \\ 0 & 0 & 0 & 0 & 0 & H_{N T}\end{array}\right)$ 


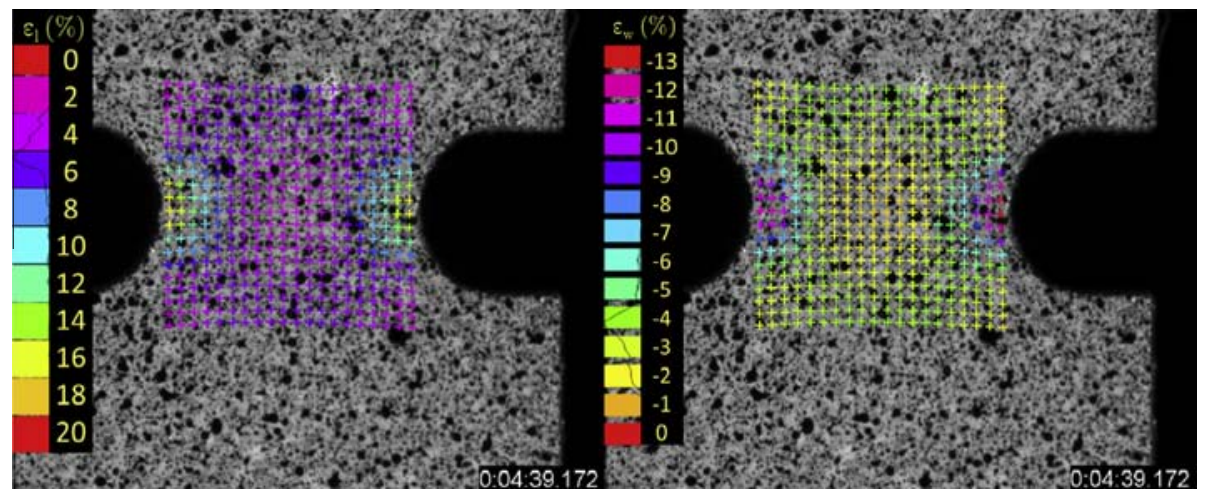

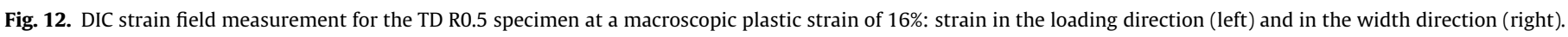

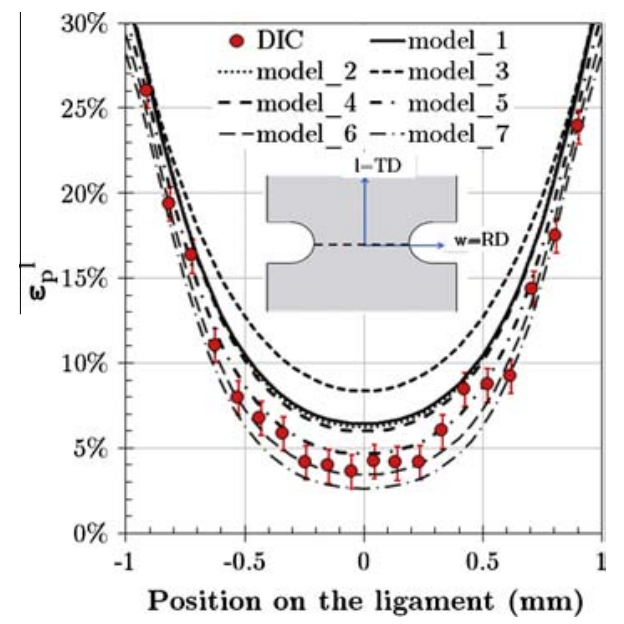

Fig. 13. Loading direction strain profile for a TD R0.5 specimen, at a macroscopic plastic strain of $18 \%$. Comparison between DIC measurements (dots) and the different models identified (black dashed lines). Model_5 is the final identified model.

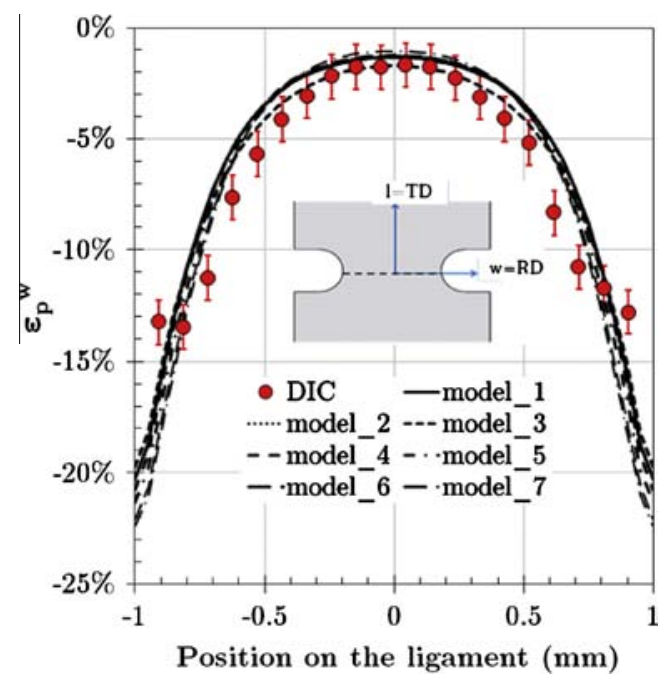

Fig. 14. Width direction strain profile for a TD R0.5 specimen, at a macroscopic plastic strain of $18 \%$. Comparison between DIC measurements (red dots) and the different models identified (black dashed lines). Model_5 is the final identified model. (For interpretation of the references to color in this figure legend, the reader is referred to the web version of this article.) so that the equivalent Hill's stress in the orthotropic directions is:

$$
\begin{aligned}
\sigma_{H}(\underline{\underline{\sigma}})= & {\left[H_{N}\left(\sigma_{T}-\sigma_{R}\right)^{2}+H_{T}\left(\sigma_{R}-\sigma_{N}\right)^{2}+H_{R}\left(\sigma_{N}-\sigma_{T}\right)^{2}\right.} \\
& \left.+2 H_{T R} \sigma_{T R}^{2}+2 H_{N T} \sigma_{N T}^{2}\right]^{0.5}
\end{aligned}
$$

The Hill coefficients were defined up to a multiplicative constant. In the Mistral module, the reference direction was the RD, so that $\sigma_{H}$ was equal to $\sigma_{R}$ for a uniaxial test along RD. With Eq. (5), the relation $H_{N}+H_{T}=1$ followed from that scaling of the tensor. Albeit physically incorrect, this method was commonly used with rather good yield surface predictions $[1,20]$. It is quite useful for thin specimens in which the mechanical properties of the normal (or radial for tubes) direction are not known. The shear components of the stress tensor could not be measured and are supposed to play no part in our tests. The isotropic Hill coefficients in the shear directions were thus considered $\left(H_{T R}=H_{R N}=H_{N T}=1.5\right)$. As observed by Maki [21], and because of the strong anisotropy of plastic flow, the anisotropic constants changed with plastic strain. A single set of Hill coefficients alone could not represent the change in yield surface and strain hardening with plastic strain. To remedy this issue, a kinematic hardening component $X$ was introduced. In this study, the loading rate was always positive and no compression tests were performed. This kinematic hardening does not refer to the real internal stress of the material but was a way to take into account plastic anisotropy at high plastic strains. The internal stress tensor evolution was given by:

$$
\frac{d[X]^{s}}{d t}=C\left[E_{C}\right] \frac{d\left[\varepsilon^{p}\right]^{s}}{d t}-D v^{*}\left[R_{D}\right][X]^{s}
$$

With $\left[E_{C}\right]$ the strain hardening tensor, $\left[R_{D}\right]$ the dynamic recovery tensor, $v^{*}$ the equivalent strain rate. $C$ and $D$ were model parameters. $\left[E_{C}\right]$ and $\left[R_{D}\right]$ have the same shape as $\left[M_{H}\right]$ so that the kinematic hardening $X$ remained fully deviatoric. An isotropic strain hardening $R$ was used to account for most of the material hardening and early softening.

$R\left(\varepsilon^{*}\right)=R_{0}+R_{1} \varepsilon^{*} \exp \left(-G_{1} \varepsilon^{*}\right)+R_{2}\left(1-\exp \left(-G_{2} \varepsilon^{*}\right)\right)$

With $\varepsilon^{*}$ the equivalent plastic strain. The $R_{i}$ coefficients are constant. The part of the stress multiplied by $R_{1}$ is meant to represent an average of the yield peak/plateau of the uniaxial stress-strain curves. Finally, the yield function was:

$f=\sigma_{H}(\underline{\underline{\sigma}}-\underline{\underline{X}})-R\left(\varepsilon^{*}\right)$

The experimental data showed that the strain rate sensitivity was the same for the $R$ and $T$ directions and was constant with strain in the strain rate range studied here. The viscoplastic strain rate was derived from a simple viscoplastic potential $\Omega$ with a Norton power law shape. 
$\Omega=\frac{K}{\alpha+1}\left(\frac{f}{K}\right)^{\alpha+1}$

$K$ is a normalizing stress and $\alpha$ is the inverse of the strain rate sensitivity $m$. The equivalent viscoplastic strain rate $v^{*}$ derives from $\Omega$ :

$v^{*}=\frac{\partial \Omega}{\partial f}=\left(\frac{f}{K}\right)^{\alpha}$

The normality rule was also considered. In that case, the time derivative of the viscoplastic strain vector is given by:

$\frac{d\left[\varepsilon^{p}\right]^{s}}{d t}=v^{*} \frac{\partial \Omega}{\partial[\sigma]^{s}}=v^{*} \frac{M_{H}\left([\sigma]^{s}-[X]^{s}\right)}{\sigma_{H}(\underline{\underline{\sigma}}-\underline{\underline{X}})}$

The equivalent viscoplastic strain $\varepsilon^{*}$ is the integral of the equivalent viscoplastic strain rate.

\subsection{Parameter identification}

In this model, 24 parameters had to be identified, 3 Hill coefficients (shear coefficients arbitrary equal to 1.5 ), 14 for the kinematic hardening, 5 for the isotropic hardening and 2 for the viscoplastic potential. Only a few parameters were independent from the others and could be easily calculated from the tests results (the strain rate sensitivity for instance). In this section, two methods of parameter determination are described. The first one was based on formalism simplifications and on the results of uniaxial tests only. The second was an optimization of the former, taking into account the results of notched specimens DIC.

\subsubsection{First set}

The first approach was to neglect the kinematic stress and identify the model parameters by fitting the TD results for the smooth specimens tests. In that case, plastic strains could be easily computed from the stress and the Hill coefficients via Eq. (11) and strain ratios were functions of the Hill coefficient only. For a TD and a RD test respectively:

$\frac{\varepsilon_{T}^{p}}{\varepsilon_{R}^{p}}=-\frac{H_{R}+H_{N}}{H_{N}}$

$\frac{\varepsilon_{R}^{p}}{\varepsilon_{T}^{p}}=-\frac{1}{H_{N}}$

Using uniaxial test DIC results and the relation $H_{N}+H_{T}=1$ from the tensor scaling, the following Hill coefficients were determined: $\left(H_{N}\right.$, $\left.H_{T}, H_{R}\right)=(0.78,0.22,0.18)$. With these values, the simulated Lankford coefficients were quite close to the experimental ones. However, with such coefficients, the difference of yield strengths in the RD and TD was not well simulated. Kinematic hardening accounts for a large part of the flow stress in recrystallized Zircaloy-4 [10] and thus Eqs. (12) and (13) might not be relevant. The following choice was then made: the Hill coefficients were to be determined for a good representation of the initial yield stress levels, and plastic anisotropy was to be taken into account by the kinematic hardening. Imposing the same value of $\sigma_{H}$ in the RD and the TD uniaxial tests and using the definition of the equivalent stress in (5) gave the following:

$\sigma_{H}^{R D}\left(\varepsilon^{p}=0.2 \%\right)=\sigma_{H}^{T D}\left(\varepsilon^{p}=0.2 \%\right) \rightarrow \sqrt{H_{N}+H_{R}}=\frac{R_{p_{0.2}}^{R D}}{R_{p_{0.2} \%}^{T D}}$

The ratio of yield strength was measured at all the strain rates used. Using the average ratio value in Eq. (14) and the Lankford coefficient determination from the TD uniaxial test, the following set of Hill coefficients was found: $\left(H_{N}, H_{T}, H_{R}\right)=(0.66,0.34,0.18)$.

The model constitutive equations were implanted in the Excel software and time integration was carried out with a finite differences pattern. The results of this integration were successfully compared with FE calculations. By plotting together the experimental and calculated stress-strain curves, it was possible to determine successively the model parameters fitting the TD tests (viscosity parameter and isotropic hardening). However, as expected, the calculated strain-stress curves in the RD exhibited too low strain hardening rates in comparison with experimental results. To account for this difference, the kinematic hardening was introduced. To facilitate identification and to limit the number of parameters, kinematic tensors were chosen with the following expression, written in the $(\mathrm{ND}, \mathrm{TD}, \mathrm{RD})$ coordinates:

$\left[E_{C}\right]=\left[R_{D}\right]=\left(\begin{array}{cccccc}2 / 3 & 0 & -2 / 3 & 0 & 0 & 0 \\ 0 & 0 & 0 & 0 & 0 & 0 \\ -2 / 3 & 0 & 2 / 3 & 0 & 0 & 0 \\ 0 & 0 & 0 & 3 / 2 & 0 & 0 \\ 0 & 0 & 0 & 0 & 3 / 2 & 0 \\ 0 & 0 & 0 & 0 & 0 & 3 / 2\end{array}\right)$

Consequently, the kinematic stress in the TD was equal to 0 for a TD uniaxial loading. For the RD, the kinematic stress was used to fill the gap between model and experiments. These kinematic tensors also implied that the ND and the RD had the same kinematic stress evolution, and thus the same strain hardening behavior, for similar loadings. The method is illustrated in Fig. 15. Viscosity and isotropic hardening parameters were still valid, the only parameters left were the C and D constants of the kinematic stress evolution (Eq. (6)). Identification was made visually by superimposing computed and experimental stress-strain curves. This led to the identification of the parameters of the first model. The difference between this model and experiments was less than $3 \%$ on all the CERTs stress-strain curves for plastic strains up to $10 \%$.

\subsubsection{Optimization}

An optimization criterion between model and experiments was chosen as the weighted sum of two variables measuring difference between model and experiments: one for the stress-strain curves and one for the strain ratios. A proprietary solver was then used to optimize the model parameters. Using this tool, other constraints could be taken into account. From the first model, several optimizations were made with different sets of varying parameters. For instance, the Hill coefficients, viscosity parameters and kinematic tensors shapes were considered as fixed and only the isotropic hardening parameters from Eq. (7) and the C and D parameters from Eq. (6) were adjusted. The following optimizations dealt with more and more degrees of freedom until all parameters were adjusted.

Different sets of parameters were thus obtained, with different Hill coefficients, isotropic hardening and kinematic stress components, all fitting quite well the experimental data for uniaxial tests and the macroscopic curves for notched specimens. This is illustrated in Figs. 4 and 11. For these macroscopic results, all the different models gave very similar results. The DIC strain data from tensile tests on notched specimens was used to identify the best model from the batch: plastic strain profiles along the ligament between the notches were measured, in the specimen axial and transverse directions and compared with predictions of the different models. FEM calculations were performed in 2D, in plane stress conditions. Due to the symmetry of the geometry, only one quarter of the specimen was meshed with linear rectangular elements, with a density leading to 40 elements on the notches ligament. Large deformations and displacements were taken into account. From the displacement-load curves, the macroscopic plastic strain $E^{p}$ was computed for the experimental tests and the calculations. Experimental and simulated strain profiles were compared at different values of $E^{p}$. Figs. 13 and 14 show an example of these comparisons. Different models leading to the same mechanical re- 


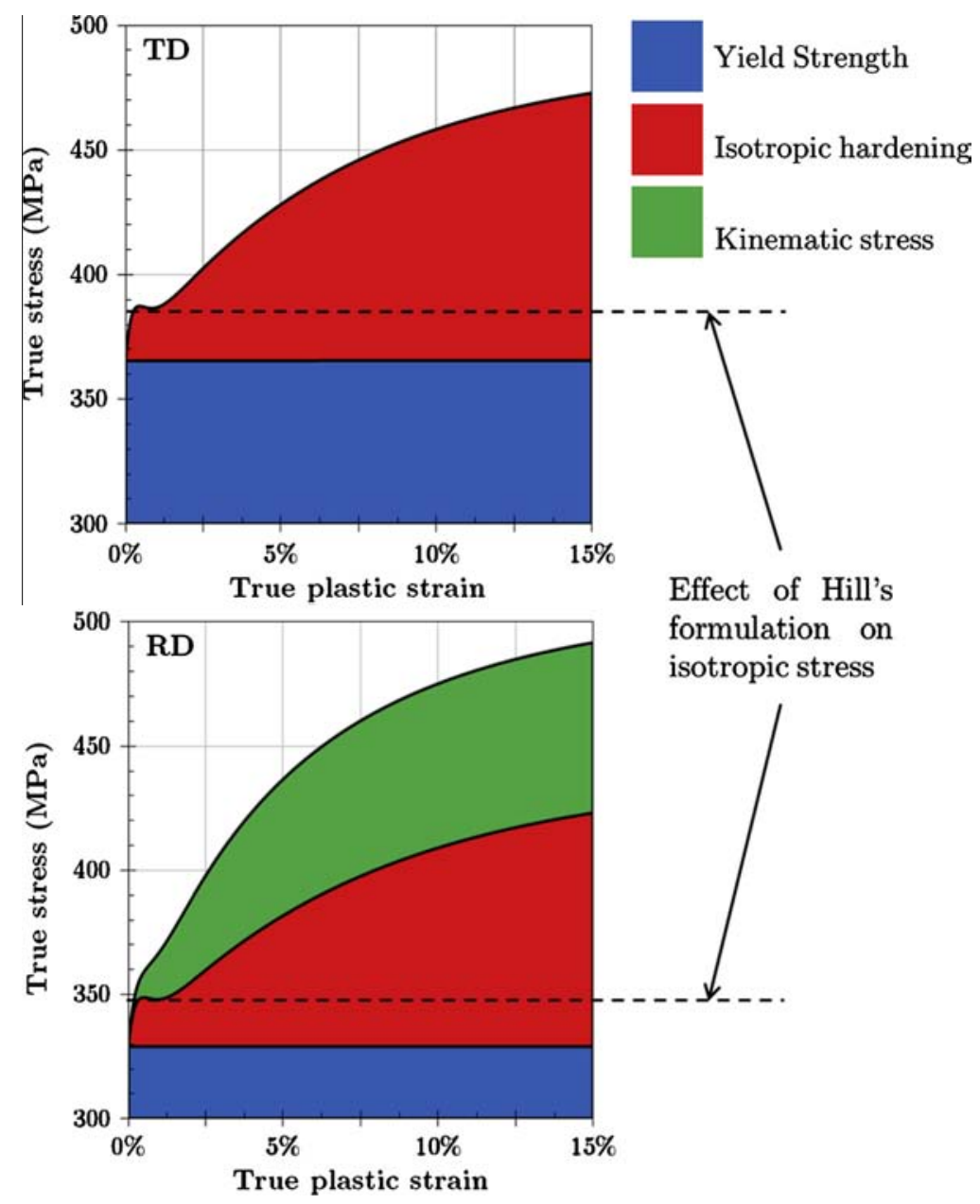

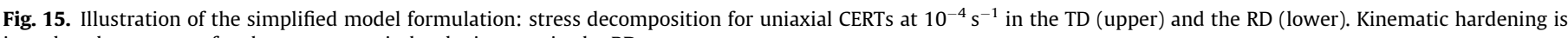
introduced to account for the greater strain hardening rate in the RD.

sponse for uniaxial tests could give quite different results for complex multi-axial loading, especially at the center of the specimens. This was a key-point in our study because subsequent I-SCC tests focused on the stress biaxiality ratio influence. This ratio was maximal at the center of the ligament, and thus our model had to give the best mechanical description in this area.

\section{Results}

From all the sets of parameter obtained with the previous identifications, the one giving the best fit to the TD R0.5 notched specimen test (highest stress biaxiality ratio) was chosen. In the Fig. 13, the selected model was number five. Surprisingly, it was obtained with the least degrees of freedom: the Hill coefficients were equal to those determined with the first set of parameters and the kinematic tensors had the simplified shape given in Eq. (15). The model parameters are presented in Table 4 . With the simplified formulation, the model only 12 parameters; only two Hill's coefficients were independent. Moreover, the initial level of isotropic hardening $R_{0}$ was disregarded (set to a value of $1 \mathrm{MPa}$ as 0 brings numerical problems) so that the yield strength was entirely determined by the Hill stress and the strain rate.

Agreement with the uniaxial CERTs is shown in Fig. 4. The model simulated very well the experiments, with an error less than $3 \%$. The differences in yield strength and hardening rate were well taken into account thanks to the Hill equivalent stress and the use of kinematic hardening. In the range of strain rate used in this study, the Norton power law was adequate for viscosity considerations. This was confirmed by the creep experiments and simulations shown in Figs. 6 and 7 for strain rates as low as $410^{-8} \mathrm{~s}^{-1}$. It should be noted that creep tests and three out of four notched specimen tests were not used in the model fitting procedure. The good agreement between experiments and model for these tests confirmed that the model was still relevant outside of the identification range.

The simulated plastic anisotropy was lower than the measured results. The strain ratio for uniaxial CERT (lateral/axial) was -0.763 for the TD and -0.716 for the RD (Fig. 5), leading to Lankford coefficients of 3.20 and 2.52 respectively whereas experimental values were 4.41 and 3.54. The trend was respected but plastic anisotropy was still underestimated.

The notched specimen macroscopic response was well predicted as illustrated in Fig. 11 for the R0.5 specimens. Prediction was better for the R0.5 specimens and for the specimens in the TD rather than the RD. A maximal error of $7.7 \%$ for all the macroscopic curves was observed, in the range of macroscopic strain where DIC was possible (Table 3). Strain profiles along the ligament between the notches were compared to the model response for all the notched specimens in Fig. 16. Like the macroscopic curves, agreement was better for the R0.5 specimens (smaller notch) than for the R1.0, and better for the TD than for the RD. The profiles shapes were well represented, especially for the R0.5 specimens for which plastic strain was essentially localized at the notch tips. 
Table 4

Values of the model parameters.

\begin{tabular}{|c|c|c|c|c|c|c|c|c|c|c|c|}
\hline \multicolumn{3}{|l|}{$\left[M_{H}\right]$} & \multicolumn{2}{|l|}{ Viscosity } & \multicolumn{2}{|l|}{$[X]^{s}$} & \multicolumn{5}{|l|}{$R\left(\varepsilon^{*}\right)$} \\
\hline$H_{N}$ & $H_{T}$ & $H_{R}$ & $K(\mathrm{MPa})$ & $\alpha=\mathrm{m}^{-1}$ & $C(\mathrm{GPa})$ & $D$ & $R_{0}(\mathrm{MPa})$ & $R_{1}(\mathrm{MPa})$ & G1 & $R_{2}(\mathrm{MPa})$ & G2 \\
\hline 0.66 & 0.34 & 0.16 & 435 & 33.4 & 2.47 & 21.2 & 1 & 118 & 305 & 109 & 13.2 \\
\hline
\end{tabular}

For the ultimate objective to study the influence of stress biaxiality ratio on iodine-induced stress corrosion cracking, attention was paid to the center of the ligament, where this ratio was maximal. The model performance was evaluated by plotting the evolutions of the local strain at the center of the ligament as a function of the macroscopic plastic strain. Results are shown in Fig. 17 for TD specimens and in Fig. 18 for RD specimens. Theoretical accuracy of the DIC is used for the error bars in these graphs. Difference of geometry between R1.0 and R0.5 led to great local strain differences for a same value of $E^{p}$. From Figs. 17 and 18, it appears that the model predictions are within the DIC precision range $( \pm 0.01)$ when local strains do not exceed $4 \%$. Beyond this limit, almost exclusively for R0.5 specimens, the model accuracy strongly depends on the specimen direction and on the considered direction: while local strain in the loading direction was well predicted for the TD specimen up to $9 \%$ of macroscopic plastic strain $E^{P}$, predictions became unreliable from $E^{P}=6 \%$ for the width direction strain. For the RD specimens, local strain in the loading direction was well predicted until $E^{P}=6 \%$, and the width strain until $4 \%$.

\section{Discussion}

Since our study dealt with thin sheets with no possibility to characterize the normal direction (ND), no effort was made to identify parameters along this direction. However, evaluating it could tell whether the chosen formalism had some physical meaning. With the approximations made, the ND would have the same strain hardening behavior as the RD. However, the yield strength would be given by:

$\sqrt{H_{T}+H_{R}} R_{p_{0.2 \%}}^{N D}=\sqrt{H_{R}+H_{N}} R_{p_{0.2 \%}}^{T D}$

The model predicts that the yield strength in the ND should be 1.28 of the TD Yield stress $\left(\mathrm{YS}_{\mathrm{TD}}\right)$. Cahoon established a relationship between yield strength and hardness measurements successfully tested for brass, steel and aluminum alloys (cubic structures), cold rolled or aged:

$\mathrm{YS}=\left(\frac{H}{3}\right) 0.1^{n}$
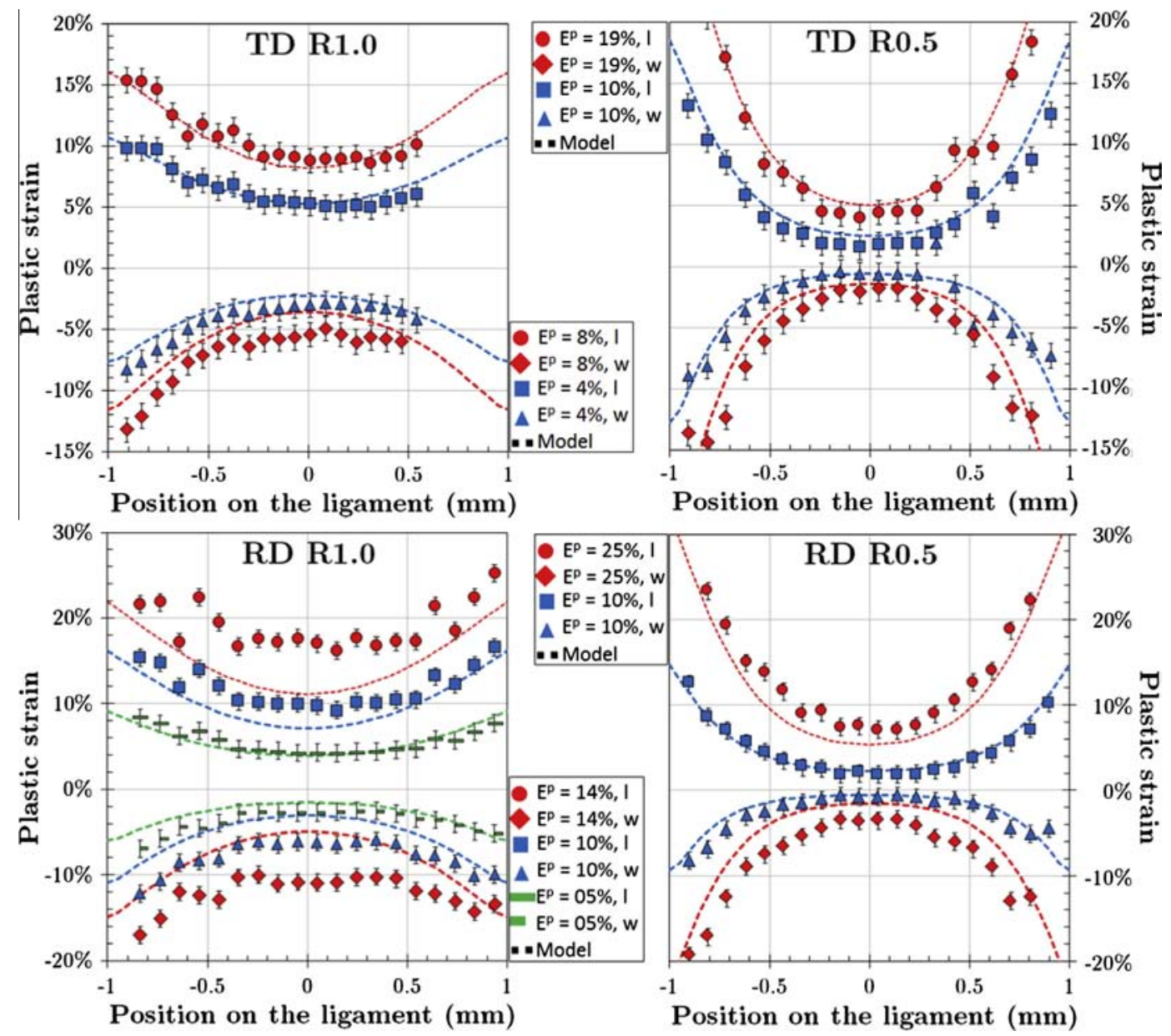

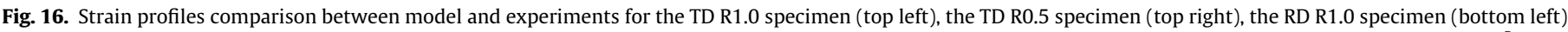
and the RD R0.5 specimen (bottom right). For each specimen type, loading direction $(l)$ and width direction ( $w$ ) are plotted at different macroscopic plastic strain $E^{P}$. 


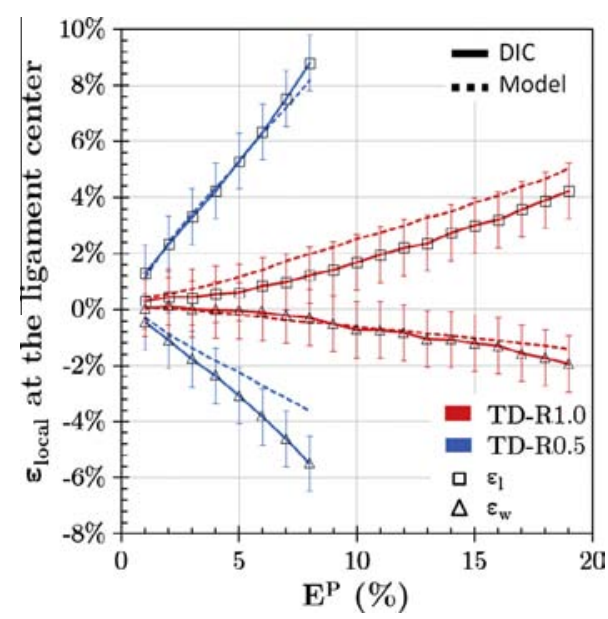

Fig. 17. Local strain measurements at the center of the ligament for the notched TD specimens as a function of macroscopic plastic strain $E^{P}$, in the loading direction ( $l=\mathrm{TD}$, squares $)$ and in the width direction ( $w=\mathrm{RD}$, triangles). Comparison with the model (dashed lines).

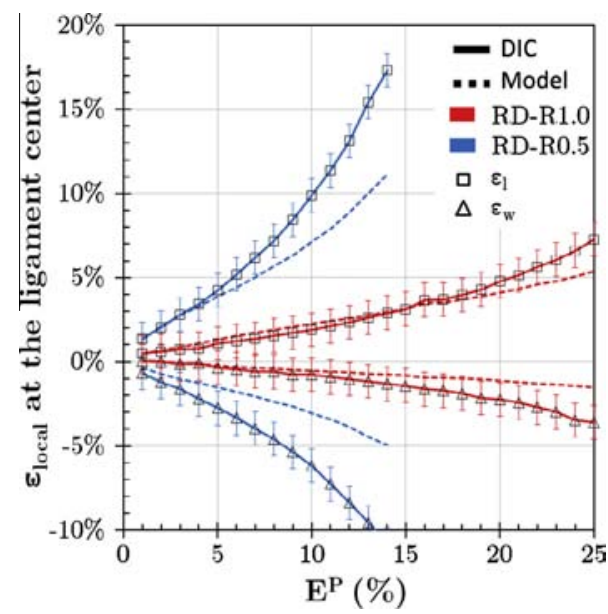

Fig. 18. Local strain measurements at the center of the ligament for the notched RD specimens as a function of macroscopic plastic strain $E^{P}$, in the loading direction ( $l=\mathrm{RD}$, squares $)$ and in the width direction ( $w=\mathrm{TD}$, triangles). Comparison with the model (dashed lines).

where $H$ was the hardness measurement by a pyramidal indenter, and $\mathrm{n}$ was the exponent in the simplified hardening law $\sigma=K \cdot \varepsilon^{n}$ [22]. Viscosity was not taken into account.

In order to evaluate the yield stress in the ND, this method was applied to the studied material. Vickers hardness measurements were performed in the TD-RD plane (210.3 HV0.2), in the RD-ND plane (171.5 HV0.2) and in the ND-TD plane (166.7 HV0.2). Values of $n$, in the RD $\left(13.410^{-2}\right)$ and the TD $\left(9.410^{-2}\right)$, were computed with the least square method, from the CERT uniaxial tests performed at $10^{-4} \mathrm{~s}^{-1}$ (Table 1). Eq. (17) predicted that the ratio of yield strength (RD divided by TD) was $89 \%$. Experimentally, this ratio was $90 \%$. With this formula, and assuming that the $n$ value for the ND was equal to the $\mathrm{n}$ value for the $\mathrm{RD}$ (as suggested by the model assumption in Eq. (15), the ND yield strength was expected to be 1.12 of $\mathrm{YS}_{\mathrm{TD}}$. From that point of view, the model overestimated the normal strength.

It seemed very unlikely that the same strain hardening behavior could be observed for the RD and the ND. Prismatic gliding is known to be the easiest activated slip system and the one with the highest deformation contribution even at $4 \%$ of plastic strain [10]. When the applied stress and the basal planes normal are parallel, the Schmidt factor for prismatic slip is close to zero.
Twinning, pyramidal and basal glide would dominate. Critical resolved shear stresses and shear hardening rates are difficult values to obtain. However one could expect these values to differ from one system to another. For instance, Turner used hardening rates of 1.1 GPa, 2.0 GPa, 2.1 GPa for prismatic, pyramidal and basal glide respectively for his polycrystalline behavior model [23]. Moreover, the Cahoon formula was established for isotropic behavior materials. In the present study, Vickers hardness indentations were not symmetrical due to the material anisotropy (Vickers indentation is not $100 \%$ directional).

Very little data is available concerning the mechanical properties in the normal direction of cold-rolled zirconium alloys sheets. Ballinger reported such properties for two sheets of stress-relieved Zircaloy-2 with different textures [24]. The evolution of yield stress and strain hardening exponent as a function of basal pole fraction in the loading direction were determined. These results are summarized in Fig. 19. Data were interpolated using the Kearns factors of the material of this study in order to check whether the variations corroborated the model predictions. As shown in Fig. 19, the extrapolation of Ballinger's data supposed that YS ${ }^{\mathrm{ND}}$ was $22 \%$ larger than $\mathrm{YS}^{\mathrm{TD}}$, quite close to the value of $28 \%$ calculated by the model. It also predicted that the strain hardening exponent for the normal direction $n^{\mathrm{ND}}$ was only $15 \%$ larger than $n^{\mathrm{RD}}$, while $n^{\mathrm{ND}}$ was more than $50 \%$ larger than $n^{\mathrm{TD}}$. The formulation assumption that $\mathrm{ND}$ and $\mathrm{RD}$ have the same hardening behavior $\left(n^{\mathrm{RD}}=n^{\mathrm{ND}}\right)$ is then strengthened.

Yield anisotropy accuracy in the RD-TD plane was evaluated using a method developed by Wheeler and Ireland. This method allowed experimental points from Knoop hardness measurements in the different planes of the sheet to be positioned on the yield surface [25]. This method supposes that the Knoop hardness number (KHN) is representative of the deviatoric stress tensor during indentation. The Knoop indenter has a flattened diamond shape, with a diagonal ratio (length/width) of 7:1. Wheeler and Ireland proposed that the ratio of the deviatoric stress components in the longitudinal and width directions was the same. Moreover, if the KHN was proportional to the magnitude of the stress tensor, it could be linked to a certain direction in the rolling and transverse stress plane. After normalization, points in the yield surface were determined. The method was originally developed and applied for Zircaloy-2. Lucas used this method on cold-rolled Zircaloy-4 sheet to study the anisotropy evolution with temperature [26]. Some of the yield stress predictions were successfully compared to experimental data at room temperature. Knoop hardness mea-

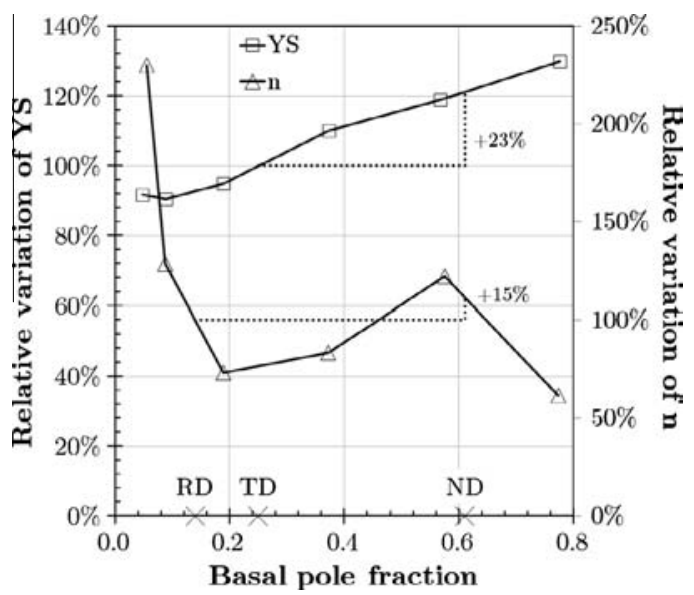

Fig. 19. Variation of yield strength (YS, squares) and strain hardening exponent ( $n$, triangles) with the basal pole fraction in the solicitation direction, for a stressrelieved Zircaloy-2, data from [24]. Variations expected for the material of the study are computed from extrapolations at basal pole fractions equal to the Kearns factors. 
Table 5

Knoop hardness (KHN) measurements for yield surface verification with Wheeler and Ireland method.

\begin{tabular}{llllc}
\hline $\begin{array}{l}\text { Indentation } \\
\text { plane }\end{array}$ & $\begin{array}{l}\text { Length } \\
\text { direction }\end{array}$ & $\begin{array}{l}\text { KHN } \\
\left(\mathrm{kg} \mathrm{mm}^{-2}\right)\end{array}$ & $\begin{array}{l}\text { Number of } \\
\text { indentations }\end{array}$ & $\begin{array}{l}\text { Standard } \\
\text { deviation }\end{array}$ \\
\hline TD-RD & TD & 223.1 & 15 & 3.8 \\
TD-RD & RD & 210.3 & 15 & 4.6 \\
RD-ND & RD & 221.6 & 18 & 15.1 \\
RD-ND & ND & 183.2 & 15 & 8.3 \\
ND-TD & ND & 148.2 & 20 & 5.6 \\
ND-TD & TD & 192.5 & 24 & 5.3 \\
\hline
\end{tabular}

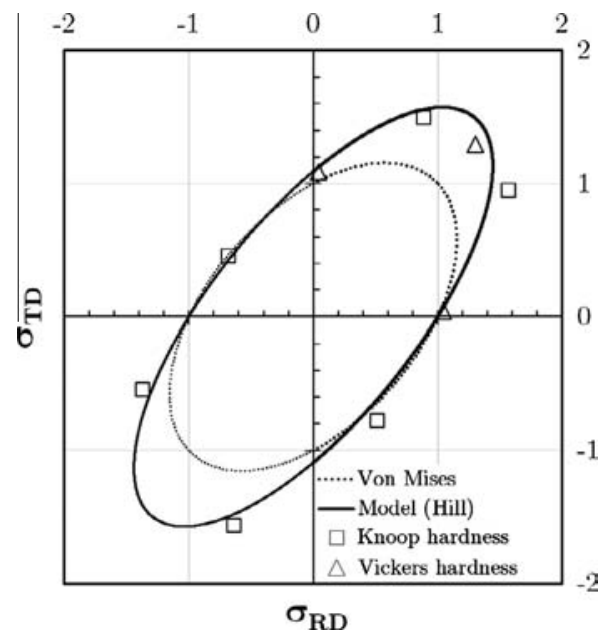

Fig. 20. Initial yield surface predicted by the fitted Hill coefficients (solid line). Comparison with the Von Mises criterion (dashed line) and the points from hardness data, Knoop (squares) and Vickers (triangles).

surements were performed in the three principal planes of the sheet, in the two principal directions of each plane. The values obtained are reported in Table 5. The method was applied and the yield surface was partially outlined. It was also extrapolated to Vickers hardness measurements, with a stress component ratio taken to be equal to the ratio of the indentation diagonals, as determined by optical observations. Results of this yield surface determination are shown in Fig. 20, along with the surface predicted by the fitted Hill equivalent stress and that from Von Mises equivalent stress. The model prediction was found to be in good agreement with the results obtained from hardness data and both clearly deviated from the Von Mises criterion for isotropic materials.

The approximations made for the model fitting led to a stress decomposition (isotropic, kinematic) that could not predict well the behavior of the ND. But the stress nature itself was questionable. Indeed, for simple fitting purposes, kinematic hardening was disregarded for uniaxial tests in the TD. For the RD, its contribution to the macroscopic stress was limited, no more than $15 \%$, to account for the difference of strain hardening between RD and TD. Geyer decomposed the macroscopic stress as a kinematic stress and an effective stress (isotropic) in multiple loading-unloading tests on recrystallized Zircaloy-4 tubes at room temperature following Handfield and Dickson's technique [10]. He found that in both axial and circumferential directions, the kinematic component in the flow stress was at least $50 \%$ after the first $1 \%$ of plastic strain. Onimus studied recrystallized Zircaloy- 4 and M5 ${ }^{\mathrm{TM}}$ tubes at $350{ }^{\circ} \mathrm{C}$ and found that the effective stress remained constant and strain hardening was due to an increase of kinematic stress [27]. Kinematic stress accounted for more than $60 \%$ of the flow stress for plastic strains between $1 \%$ and $2 \%$. Delobelle established a thorough anisotropic mechanical behavior model of recrystallized and stress-relieved Zircaloy- 4 tubes at $350{ }^{\circ} \mathrm{C}$, based on numerous and various tests (monotonic and cyclic, uniaxial and multiaxial) [20]. The good cyclic stability of the recrystallized alloy led him to consider a constant isotropic hardening and a large kinematic strain hardening. Clearly the formalism of the identified model in the present study was is consistent with this result. However, the goal of this model is to describe the mechanical fields during stress corrosion cracking at low plastic strains under monotonic loading. The focus was thus put on best-fitting identifications.

Two complementary and easy-to-implement ways of improving the model physics were contemplated. New CERTs could be performed, at intermediary angles between $0^{\circ}$ (RD) and $90^{\circ}$ (TD). As previously mentioned, mechanical properties varied with the tensile directions and these variations were not the same for all levels of plastic strain $[11,12]$ meaning once again that the Hill's stress alone could not account for these differences. Putting these tests in the optimization tool could give more realistic anisotropy coefficients. Moreover, with these tests, the Hill coefficients could be identified without the help of Lankford coefficients and thus be more realistic. Another way of proceeding would be to impose the kinematic stress evolution in the optimization, or at least to make it a constraint for the criterion calculation. Since no compression tests could be made on the material thin sheet, an approach similar to Onimus' and Geyer's could be adopted. Since the model constitutive equations were implemented in a spreadsheet, all sorts of numeric constraints could be applied. DIC measurements on notched specimens were used to choose between different optimization solutions. Alternative inverse fitting procedure could be possible based on FEM simulations of notched specimen tensile tests and strain field determination by DIC. This would require much more calculation time than the simple identification presented here.

\section{Conclusion}

The present work was part of a study of stress biaxiality effects on the initiation of I-SCC cracks in a recrystallized Zircaloy-4 thin sheet. Based on several mechanical tests at room temperature, an anisotropic viscoplastic mechanical model was developed and successfully fitted.

- Due to the crystallographic texture, the material behavior was strongly anisotropic. The rolling direction (RD) was found to exhibit a $10 \%$ lower yield strength than the transverse direction (TD), but a higher strain hardening rate, so that its ultimate stress was higher by $5 \%$. A static aging peak (TD) or plateau (RD) was observed at the onset of plasticity.

- DIC strain field measurements were carried out on smooth specimens to study plastic anisotropy and experimental Lankford coefficients were computed, $\mathrm{L}_{\mathrm{RD}}=3.54$ for the $\mathrm{RD}$ and $\mathrm{L}_{\mathrm{TD}}=4.41$ for the TD.

- The material viscosity was studied using tests at different strain rates. A strain rate sensitivity coefficient, $m$ of 0.030 was found. Creep tests were carried out for stresses around the yield strength; the results confirmed a constant $m$ value for the whole strain rate domain of the study $\left(510^{-8}-10^{-2} \mathrm{~s}^{-1}\right)$.

- From these results, a model formulation was proposed with a Hill equivalent stress to describe the yield anisotropy, a Norton power law for the viscosity, an isotropic hardening for most of the strain hardening and a kinematic stress to describe the hardening anisotropy.

- The macroscopic curves were well predicted, especially for smooth specimens at all constant strain rates, and for low plastic strains, with an average error less than $2 \%$. Local 
strain predictions at the center of notched specimens were within the DIC method accuracy for macroscopic strains lower than $5 \%$.

- In spite of the restricted number of test directions, the final model had some physical macroscopic consistency. The yield surface predicted by the fitted Hill coefficients $(0.66$, $0.34,0.18$ ) was in good agreement with data from hardness measurements. The predicted mechanical behavior in the normal direction was consistent with the few studies available. However, the stress decomposition (isotropic + kinematic) differed from observations made in other studies.

In conclusion, the model can successfully predict local stress and strain fields developed during room temperature monotonic tensile tests on smooth and notched specimens at low plastic strains over a wide range of strain rates.

\section{Acknowledgements}

The authors would like to thank AREVA-CEZUS and J.-M. Cloué for providing the material sheets, J.-L. Béchade for XRD analysis, E. Rouesne for EBSD masurements, J.-F. Lecot, J.-P. Pizzanelli and B. Bernicchia for technical support. R. Limon is also acknowledged for fruitful discussions.

\section{References}

[1] M. Nakatsuka, Y. Hayashi, J. Nucl. Mater. 105 (2-3) (1982) 159-171.

[2] B.C. Syrett, R.L. Jones, D. Cubicciotti, J. Nucl. Mater. 96 (1-2) (1981) 160-168.
[3] T.M. Angeliu, et al., Development of Fracture Mechanics Method to Evaluate Iodine Stress Corrosion Cracking of Zirconium Alloys. in: Top Fuel, Paris, France, 2009.

[4] I. Schuster, C. Lemaignan, J. Nucl. Mater. 189 (1992) 157-166.

[5] K. Hirao, T. Yamane, Y. Minamino, J. Mater. Sci. Lett. 7 (6) (1988) 623-624.

[6] S.B. Goryachev et al., J. Nucl. Mater. 199 (1-2) (1992) 50-60.

[7] M. Bornert, CorrelManuV.

[8] M. Le Saux, Comportement et Rupture de Gaines en Zircaloy-4 Détendu Vierges, Hydrurées ou Irradiées en Situation Accidentelle de Type RIA, 2008, Ecole des Mines de Paris.

[9] J.W. Dunlop et al., Mater. Sci. Eng. A 443 (2007) 77-86.

[10] P. Geyer, Comportement Elasto-viscoplastique de Tubes en Zircaloy-4: Approche Expérimentale et Modélisation Micromécanique, Ecole nationale supérieure des mines de Paris, Paris, France, 1999.

[11] L. Allais, V. Vaubert, I. Tournié. Anisotropie de Comportement d'une Tôle de Zirconium Alpha 702, in: Journées d'études Propriétés-Microstructures, 1996.

[12] M. Grange, J. Besson, E. Andrieu, Metall. Mater. Trans. A 31 (3) (2000) 679-690.

[13] S.T. Mahmood, K.L. Murty, J. Mater. Eng. 11 (1989) 315-329.

[14] K. Elbachiri, et al., Influence de la Microstructure des Alliages de Zirconium sur leur Sensibilité à la Vitesse de Déformation et à la Température. in: 16eme Congrès Français de Mécanique, Nice, France, 2003.

[15] C. Pujol, Etudes des mécanismes de déformatio en traction et fluage du $\mathrm{Zr}$ alpha entre 20 et $300^{\circ} \mathrm{C}$, Ecole des Mines de Paris, 1994, p. 293.

[16] CEA.Cast3M. <http://www-cast3m.cea.fr/>.

[17] R. Hill, The Mathematical Theory of Plasticity, Clarendon Press, Oxford, 1950

[18] M. Le Saux et al., J. Nucl. Mater. 378 (1) (2008) 60-69.

[19] L. Fournier et al., J. Nucl. Mater. 384 (1) (2009) 38-47.

[20] P. Delobelle et al., J. Nucl. Mater. 238 (2-3) (1996) 135-162.

[21] H. Maki, M. Ooyama, J. Nucl. Sci. Technol. 12 (7) (1975) 423-435.

[22] J.R. Cahoon, W.H. Broughton, A.R. Kutzak, Metall. Trans. 2 (7) (1971) 19791983.

[23] P.A. Turner, N. Christodoulou, C.N. Tomé, Int. J. Plast 11 (3) (1995) 251-265.

[24] R.G. Ballinger, R.M. Pelloux, J. Nucl. Mater. 97 (3) (1981) 231-253.

[25] R.G. Wheeler, D.R. Ireland, Electrochem. Technol. 4 (1966) 313-317.

[26] G.E. Lucas, A.L. Bement, J. Nucl. Mater. 58 (2) (1975) 163-170.

[27] F. Onimus et al., J. Nucl. Mater. 358 (2-3) (2006) 176-189. 